Efficient Vol 1 (1) (2018): 59-68 DOI: https://doi.org/10.15294/efficient.v1i1.27221

\title{
Faktor-Faktor yang Mempengaruhi Produktivitas Tenaga Kerja Produksi di PT. Hair Star Indonesia
}

\author{
Adika Nur Rahmawan $^{1 凶}$, Sucihatiningsih D.W.P ${ }^{2}$ \\ Jurusan Ekonomi Pembangunan,Fakultas Ekonomi, Universitas Negeri Semarang \\ Permalink/DOI: https://doi.org/10.15294/efficient.vii1.27221
}

Received: July 2017; Accepted: October 2017; Published: January 2018

\begin{abstract}
This study aimed to analyze the relationship between the provision of incentives to the productivity, allowances with productivity levels, and age with the level of labor productivity of the production department in PT. Hair Star Indonesia. The data collection is done by distributing questionnaires, interviews, and documentation. Collected data were analyzed with quantitative approach that includes the step of grouping the data, tabulation, data presentation, and conclusion. Data were analyzed using quantitative analysis, regression testing, and classical assumption test using EViews 6. Based on the survey results revealed that the provision of incentives and allowances have a positive and significant effect on labor productivity of the production department in PT. Hair Star Indonesia. Age has a negative and significant impact on labor productivity production in PT. Hair Star Indonesia. The company should pay attention to the age of labor, labor age are included in the age category of the labor force can produce productivity and good work.
\end{abstract}

Keywords: : Incentives; Allowances; Ages; Productivity; Labor

\begin{abstract}
Abstrak
Penelitian ini bertujuan untuk menganalisis pengaruh antara pemberian insentif, pemberian tunjangan dan usia dengan tingkat produktivitas tenaga kerja bagian produksi PT. Hair Star Indonesia. Penelitian ini juga bertujuan untuk mengetahui karakteristik tenaga kerja produksi PT. Hair Star Indonesia. Pengumpulan data dilakukan dengan menyebarkan kuesioner, wawancara, dan dokumentasi. Data yang terkumpul selanjutnya dianalisis dengan pendekatan kuantitatif yang meliputi langkah pengelompokkan data, tabulasi data, penyajian data, dan penarikan kesimpulan. Data dianalisis menggunakan analisis kuantitatif, uji regresi, dan uji asumsi klasik menggunakan EViews 6. Berdasarkan hasil penelitian diketahui bahwa pemberian insentif dan tunjangan memiliki pengaruh positif dan signifikan terhadap produktivitas tenaga kerja produksi PT. Hair Star Indonesia. Usia memiliki pengaruh negatif dan signifikan terhadap produktivitas tenaga kerja produksi PT. Hair Star Indonesia. Sebaiknya perusahaan memperhatikan usia tenaga kerja, usia tenaga kerja yang masuk dalam kategori usia angkatan kerja dapat menghasilkan produktivitas dan hasil kerja yang baik.
\end{abstract}

Kata Kunci: Insentif; Tunjangan; Usia; Produktivitas; Tenaga Kerja.

How to Cite: Rahmawan, A., \& Prajanti, S. (2018). Faktor-Faktor yang Mempengaruhi Produktivitas Tenaga Kerja Produksi di PT. Hair Star Indonesia. EFFICIENT Indonesian Journal of Development Economics, 1(1), 59-68. https://doi.org/10.15294/efficient.vii1.27221

(c) 2018 Universitas Negeri Semarang. All rights reserved

Alamat Korespondensi :

Alamat: Gedung L2 Lantai 2 FE Unnes

Kampus Sekaran, Gunungpati, Semarang, 50229

E-mail : jurnalefficient@gmail.com 


\section{PENDAHULUAN}

Sumber daya manusia merupakan salah satu faktor yang sangat penting dalam suatu perusahaan, oleh karena itu sumber daya manusia harus dikelola dengan baik untuk meningkatkan efektivitas dan efisiensi organisasi (Hariandja, 2002). Sumber daya manusia yang baik sangat berpengaruh terhadap kinerja perusahaan. Pembinaan, pengarahan, serta motivasi perlu diberikan kepada tenaga kerja agar dapat memberikan kontribusi yang baik bagi perusahaan. Secara umum sumber daya manusia dapat dilihat dari dua aspek, yakni kuantitas dan kualitas sumber daya manusia. Dalam persaingan global saat ini, diperlukan kombinasi keduanya untuk menghasilkan produk yang berkualitas, berdaya saing, dan terjangkau.

Peningkatan produktivitas dapat dicapai dengan menekan sekecil-kecilnya segala macam biaya termasuk dalam memanfaatkan sumber daya manusia dan meningkatkan output sebesarbesarnya. Meningkatkan produktivitas dapat juga dilakukan dengan pemberian insentif dan tunjangan sebagai motivator bagi tenaga kerja. Usia tenaga kerja juga perlu diperhatikan agar produktivitas tenaga kerja senantiasa meningkat, karena secara fisik kemampuan bekerja diukur dengan usia. Insentif adalah perangsang bagi para tenaga kerja untuk melaksanakan kerja sesuai atau lebih tinggi dari standar yang telah ditetapkan. Jumlah insentif yang diberikan harus sesuai dengan pencapaian selama periode tertentu dan sesuai dengan kesepakatan yang telah disetujui oleh kedua belah pihak.

Tunjangan adalah unsur balas jasa yang diberikan secara langsung kepada tenaga kerja dan dapat diketahui secara pasti. Tunjangan yang biasa diberikan oleh perusahaan yaitu tunjangan jabatan, kesejahteraan, makan, transport, dan tunjangan lain tergantung dari kemampuan perusahaan dalam memberikan tunjangan yang layak bagi tenaga kerjanya.

PT. Hair Star Indonesia memiliki tenaga kerja produksi di bagian pembuatan rambut atau bulu mata palsu sintetis dan rambut/bulu mata palsu manusia sebanyak 600 tenaga kerja dengan dibekali mesin-mesin sebagai penunjang. Output rata-rata per tahun yang dapat dihasilkan oleh PT. Hair Star Indonesia adalah $\mathbf{2 . 2 0 0 . 0 0 0}$ set/tahun

Definisi pembangunan menurut Meier (1995) adalah suatu proses saat pendapatan per kapita suatu negara meningkat dalam jangka waktu yang panjang diiringi dengan meningkatnya kualitas hidup masyarakat dan meratanya distribusi pendapatan yang diterima oleh masyarakat. Tujuan pembangunan ekonomi untuk menaikkan pendapatan nasional riil dan untuk meningkatkan produktivitas (Irawan dan Suparmoko, 1992).

Menurut Simanjuntak (1998) sumber daya manusia atau human resources mengandung pengertian usaha kerja atau jasa yang dapat diberikan dalam proses produksi.

Tenaga kerja adalah penduduk dalam usia kerja (berusia 15 s/d 64 tahun). Batas usia kerja yang berlaku di Indonesia adalah berumur $15 \mathrm{~s} / \mathrm{d}$ 64 tahun. Menurut pengertian ini, setiap orang yang mampu bekerja disebut sebagai tenaga kerja (Mulyadi 2003:59).

Menurut Firmansyah (2015:45) usia seseorang dapat mencerminkan kemampuan dan kondisi seseorang secara fisik, yang memungkinkan menjadi penentu tingkat produktivitas kerja seseorang. Semakin bertambahnya usia seseorang maka kemampuan dan kekuatan fisik akan berkurang yang menyebabkan produktivitas kerjanya menurun. Pada umumnya, tenaga kerja yang berusia tua mempunyai tenaga fisik yang lemah dan terbatas, 
sebaliknya tenaga kerja yang berusia muda mempunyai kemampuan fisik yang kuat (Amron, 2009:2).

Menurut Sumarsono (2003:63) produktivitas adalah perbandingan antara hasil yang dicapai (output) dengan keseluruhan sumber daya yang digunakan (input) dalam jangka waktu tertentu.

Insentif adalah suatu sarana memotivasi berupa materi, yang diberikan sebagai suatu perangsang para tenaga kerja agar dalam diri mereka timbul semangat untuk meningkatkan produktivitas (Gorda, 2004). Sedangkan Harsono (2004) berpendapat, insentif adalah sistem kompensasi dimana jumlah yang diberikan tergantung pada hasil yang dicapai.

Menurut Moekijat (1999) tunjangan adalah balas jasa tidak langsung yang diberikan perusahaan kepada tenaga kerjanya diluar upah dan gaji guna meningkatkan produktivitas. Sedangkan menurut Hasibuan (1997) tunjangan adalah kompensasi tambahan (finansial atau non finansial) yang diberikan berdasarkan kebijakan perusahaan terhadap semua tenaga kerja untuk meningkatkan kesejahteraan mereka. Berdasarkan Surat Edaran Menteri Tenaga Kerja Republik Indonesia No. SE-o7/MEN/199o Tahun 1990 tunjangan terbagi dalam 2 macam yaitu tunjangan tetap dan tunjangan tidak tetap.

\section{METODE PENELITIAN}

\section{Populasi dan Sampel}

Populasi adalah keseluruhan objek penelitian atau objek yang akan diteliti. Populasi yang diteliti dalam penelitian ini adalah seluruh tenaga kerja produksi bagian pembuatan rambut/bulu mata palsu sintetis dan manusia PT.
Hair Star Indonesia sebanyak 600 orang. Kemudian sampel yang akan diteliti dihitung menggunakan rumus Slovin (Sevilla dkk, 1960:182) sebagai berikut:

$n=\frac{N}{N \cdot e^{2}+1}$

$n=\frac{600}{600 \times 0.01+1}$

$\boldsymbol{n}=\frac{600}{7}$

$\boldsymbol{n}=86$

Sampel yang diteliti adalah sebagian dari tenaga kerja produksi bagian pembuatan rambut/bulu mata palsu sintetis dan manusia PT. Hair Star Indonesia sebanyak 86 orang.

\section{Teknik Pengumpulan Data}

Metode pengumpulan data merupakan cara yang digunakan untuk memperoleh data yang dibutuhkan dalam sebuah penelitian. Penelitian ini menggunakan data primer dan sekunder. Data primer adalah data yang diperoleh secara langsung dari lapangan oleh peneliti, sedangkan data sekunder diperoleh dari studi pustaka. Pengambilan data primer dalam penelitian ini melalui proses sebagai berikut:

\section{Kuesioner}

Kuesioner adalah teknik pengumpulan data yang dilakukan dengan cara memberi seperangkat pertanyaan tertulis kepada responden untuk dijawabnya (Sugiyono, 2009). Metode ini digunakan untuk mencari data primer dari tenaga kerja produksi PT. Hair Star Indonesia.

\section{Dokumentasi}

Dokumentasi adalah teknik mencari data mengenai hal-hal atau variabel yang berupa gambar, catatan, buku, majalah, agenda dan lain sebagainya. Peneliti menggunakan metode 
dokumentasi berupa foto kondisi para tenaga kerja ditempat kerja.

\section{Teknik Pengolahan Data dan Analisis Data}

Alat analisis yang digunakan dalam penelitian ini yaitu menggunakan program EViews 6 dengan menggunakan teknik analisis data sebagai berikut:

1. Analisis Regresi Linear Berganda

Analisis regresi linear berganda adalah sebuah regresi yang menggunakan lebih dari satu variabel. Analisis regresi merupakan suatu teknik untuk membangun persamaan garis lurus dan menggunakan persamaan tersebut untuk membuat perkiraan.

2. Uji Parsial (Uji T)

Analisis uji t digunakan untuk mengetahui pengaruh variabel independen yaitu insentif, tunjangan dan usia terhadap variabel dependen yaitu produktivitas tenaga kerja. Pengujian yang dilakukan dalam penelitian ini adalah pengujian satu arah, karena memiliki dasar teori yang kuat mengenai bagaimana pengaruh variabel independen terhadap variabel dependen.

3. Uji Signifikansi Simultan (Uji F)

Analisis uji f digunakan untuk mengetahui pengaruh variabel independen yaitu insentif, tunjangan dan usia secara simultan terhadap variabel dependen yaitu produktivitas tenaga kerja.

4. Uji Asumsi Klasik

Dalam melakukan analisis regresi berganda dengan metode OLS, maka pengujian model terhadap asumsi klasik harus dilakukan. Uji asumsi klasik tersebut antara lain sebagai berikut: a. Uji Normalitas

Deteksi normalitas bertujuan untuk menguji apakah dalam model regresi, variabel pengganggu memiliki distribusi normal atau tidak. Cara mendeteksinya adalah dengan melihat normal probability plot yang membandingkan distribusi dari data sesungguhnya dengan distribusi kumulatif dari distribusi normal.

b. Uji Mulkolinearitas

Deteksi Mulkolinearitas adalah hubungan linear antar variabel independen. Dalam asumsi regresi linear klasik, antar variabel independen tidak diijinkan untuk saling korelasi. Adanya multikolinearitas akan menyebabkan besarnya varian koefisien regresi yang berdampak pada lebarnya interval kepercayaan terhadap variabel bebas yang digunakan.

c. Uji Heteroskedastistas

Deteksi heteroskedastisitas bertujuan menguji apakah dalam model regresi terjadi ketidaksamaan variance dari residual satu pengamatan kepengamatan lain. Jika variance dari residual satu pengamatan kepengamatan lain tetap, maka disebut homoskedastisitas dan jika berbeda disebut heteroskedastisitas.

d. Uji Autokorelasi

Uji autokorelasi digunakan untuk mengetahui ada atau tidaknya penyimpangan asumsi klasik autokorelasi yaitu korelasi yang terjadi antara residual pada satu pengamatan dengan pengamatan lain pada model regresi.

\section{HASIL DAN PEMBAHASAN}

Untuk mengetahui pengaruh pemberian insentif, tunjangan dan usia tenaga kerja terhadap tingkat produktivitas tenaga kerja di PT. Hair Star Indonesia, dilakukan penyebaran kuesioner terhadap 86 responden yang menjadi sampel penelitian, kemudian data yang diperoleh diolah menggunakan software EViews 6. 


\section{Analisis Data}

Perhitungan analisis regresi linear berganda yang telah dilakukan menunjukkan besarnya pengaruh variabel independen terhadap variabel dependen. Hal ini ditunjukkan oleh nilai koefisien determinasi (R2) sebesar 0.9429. Dengan demikian insentif, tunjangan, dan usia secara bersama-sama mempunyai pengaruh yang signifikan terhadap tingkat produktivitas tenaga kerja produksi PT. Hair Star Indonesia sebesar 94.29\% sedangkan sisanya sekitar $5.71 \%$ dijelaskan oleh variabel-variabel lain yang tidak termasuk dalam penelitian ini.

Maka dapat disimpulkan bahwa nilai probabilitas signifikan variabel insentif adalah o.oooo lebih kecil dibandingkan nilai $\alpha=5 \%$
(0.0000 < 0.05) artinya variabel insentif berpengaruh positif dan signifikan terhadap variabel produktivitas. Koefisien regresi sebesar 71.54 artinya setiap kenaikan $1 \%$ dapat meningkatkan produktivitas sebesar 71.54\%. Nilai probabilitas signifikan variabel tunjangan adalah 0.0324 lebih kecil dibandingkan nilai $\alpha=5 \%$ ( $0.0324<0.05)$ artinya variabel tunjangan berpengaruh positif dan signifikan terhadap variabel produktivitas. Koefisien regresi sebesar 0.2888 artinya setiap kenaikan 1 angka dapat meningkatkan produktivitas sebesar 0.2888. Nilai probabilitas signifikan variabel usia adalah 0.4410 lebih besar dibandingkan nilai $\alpha=5 \%$ ( $0.4410>$ 0.05 ) artinya variabel usia berpengaruh negatif terhadap produktivitas karena nilai probabilitas diatas $5 \%$.

\section{Uji Asumsi Klasik}

Tabel 1. Uji Multikolinearitas

\begin{tabular}{lll}
\hline \multicolumn{2}{l}{ Examination of Partial Correlation } & \\
\hline $\mathrm{R}^{2}$ Model Utama & $\mathrm{R}^{2}$ Model Penjelas & Kesimpulan \\
& $\mathrm{R}^{2}$ (Ln Insentif, Tunjangan, Umur) & Bebas \\
& $=0.348996$ & Multikolinearitas \\
$\mathrm{R}^{2}$ (Ln Insentif, Tunjangan, & $\mathrm{R}^{2}$ (Tunjangan, Ln Insentif, Umur) & Bebas \\
Umur) = 0.986730 & $=0.348816$ & Multikolinearitas \\
& $\mathrm{R}^{2}$ (Umur, Tunjangan, Ln Insentif) & Bebas \\
& $=0.000466$ & Multikolinearitas \\
\hline
\end{tabular}

Sumber : Data Diolah eviews 6

Uji multikolinearitas menunjukkan bahwa $\quad \mathrm{R}^{2}$ variabel penjelas, maka model ini terbebas dari $\mathrm{R}^{2}$ model utama tidak ada yang lebih besar dari masalah multikolinearitas.

\section{Uji Autokorelasi}

Tabel 2. Uji Autokorelasi

Breusch-Godfrey Serial Correlation LM Test:

\begin{tabular}{lcclll}
\hline \hline & & 2.0712 & & & 0.132 \\
F-statistic & 27 & 4.1841 & Prob. F(2,81) & 7 & 0.123 \\
Obs*R-squared & 76 & & Prob. Chi-Square(2) & 4 & \\
\hline \hline
\end{tabular}

Sumber: Data diolah eviews 6 
Berdasarkan dari tabel autokorelasi, nilai maka model ini terbebas dari masalah Prob. Chi-Square(2) sebesar $0.1234>0.10$ autokorelasi.

\section{Uji Heteroskedastisitas}

Tabel 3.Uji Heteroskedastisitas

Heteroskedasticity Test: Breusch-Pagan-Godfrey

\begin{tabular}{|c|c|c|c|c|c|}
\hline & & 4.7056 & & & 0.004 \\
\hline \multirow[t]{2}{*}{ F-statistic } & 67 & & Prob. F(3,82) & 4 & \\
\hline & & 12.631 & & & 0.005 \\
\hline \multirow[t]{2}{*}{ Obs ${ }^{*} R$-squared } & 08 & & Prob. Chi-Square(3) & 5 & \\
\hline & 569 & 16.592 & Prob. Chi-Square(3) & 9 & 0.000 \\
\hline
\end{tabular}

Sumber: Data diolah eviews 6

Berdasarkan tabel heteroskedastisitas dapat diketahui bahwa nilai Prob. Chi-Square(3) sebesar $0.0055>0.10$ maka dinyatakan model ini terbebas dari masalah heteroskedasitas.

\section{Pengujian Statistik}

1. Koefisien Determinasi

Dari hasil perhitungan dapat diketahui bahwa koefisien determinasi $\left(\mathrm{R}^{2}\right)$ yang diperoleh sebesar 0.942973 Hal ini menunjukan bahwa variabel insentif, tunjangan, dan usia dapat menerangkan $94.29 \%$ terhadap variabel produktivitas tenaga kerja pada tenaga kerja produksi PT. Hair Star Indonesia, sedangkan sisanya $5.71 \%$ dapat dijelaskan oleh variabel lain yang tidak dimasukkan dalam model analisis di penelitian ini.

2. Uji Parsial (Uji T)

Parameter yang digunakan untuk uji $\mathrm{t}$ dalam penelitian ini adalah dengan membandingkan antara t-hitung dengan t-tabel. Hasilnya adalah sebagai berikut:

a. Nilai t-hitung variabel insentif adalah 28.35685 lebih besar dari nilai t-tabel yaitu 1.66365. Artinya hipotesis yang menyatakan bahwa variabel insentif diduga berpengaruh positif terhadap variabel produktivitas tenaga kerja diterima.

b. Nilai t-hitung variabel tunjangan adalah 2.176613 lebih besar dari nilai t-tabel yaitu 1.66365. Artinya hipotesis yang menyatakan bahwa variabel tunjangan diduga berpengaruh positif terhadap variabel produktivitas tenaga kerja diterima.

c. Nilai t-hitung variabel usia adalah 0.774221 lebih kecil dari nilai t-tabel yaitu $\mathbf{1 . 6 6 3 6 5}$. Artinya hipotesis yang menyatakan bahwa variabel usia diduga berpengaruh positif terhadap variabel produktivitas tenaga kerja ditolak.

\section{Uji Signifikansi Simultan (Uji F)}

Tabel 4.Estimasi Uji F

\begin{tabular}{|c|c|c|}
\hline F-statistic & Prob. (F-statistic) & Prob. 5\% \\
\hline 451.9730 & 0.000000 & 0.05 \\
\hline
\end{tabular}

Sumber : Data Diolah eviews 6 
Hasil dari uji f menunjukan bahwa variabel independen yang digunakan berpengaruh secara bersama-sama terhadap variabel dependen. Hal tersebut dapat diketahui dengan membandingkan nilai Prob. (F-Statistic) sebesar $0.000000<5 \%$.

Hasil intrepretasi dari masing-masing variabel independen yaitu insentif, tunjangan, dan usia terhadap variabel dependen yaitu produktivitas tenaga kerja dijelaskan sebagai berikut:

\section{Pengaruh Variabel Insentif Terhadap Variabel Produktivitas.}

Hasil penelitian menunjukkan bahwa insentif memiliki pengaruh positif dan signifikan terhadap produktivitas tenaga kerja produksi PT. Hair Star Indonesia. Koefisien regresi insentif sebesar 71.54 menyatakan bahwa setiap pertambahan insentif sebesar $1 \%$ akan menyebabkan produktivitas bertambah sebesar $71.54 \%$.

Dengan kata lain, semakin tinggi insentif yang diberikan kepada tenaga kerja maka semakin tinggi pula produktivitas tenaga kerja.

Pengaruh Variabel Tunjangan Terhadap Variabel Produktivitas.

Hasil penelitian menunjukkan bahwa tunjangan memiliki pengaruh positif dan signifikan terhadap produktivitas tenaga kerja produksi PT. Hair Star Indonesia. Koefisien regresi tujangan adalah sebesar 0.2888 yang artinya adalah setiap kenaikan 1 angka dapat meningkatkan produktivitas sebesar $\mathbf{0 . 2 8 8 8 .}$

Pengaruh Variabel Usia Terhadap Variabel Produktivitas, hasil dari penelitian yang telah dilakukan didapatkan nilai probabilitas signifikan variabel usia adalah 0.4410 yang lebih besar dibandingkan nilai $\alpha=5 \%(0.4410>0.05)$ yang artinya variabel usia berpengaruh negatif dan signifikan terhadap produktivitas tenaga kerja PT. Hair Star Indonesia. 16.28\% tenaga kerja berusia antara 15-24 tahun, 27.91\% tenaga kerja berusia antara 25-34 tahun, dan 29.07\% tenaga kerja berusia antara 35-44 tahun dan 26.74\% tenaga kerja berusia antara 45-54 tahun. Semakin tinggi usia tenaga kerja tidak diimbangi dengan tingkat produktivitas yang dihasilkan, dengan kata lain produktivitas tenaga kerja produksi PT. Hair Star Indonesia semakin menurun seiring bertambahnya usia.

\section{SIMPULAN}

Dari penelitian yang dilakukan dapat disimpulkan bahwa insentif berpengaruh positif dan signifikan terhadap produktivitas tenaga kerja produksi PT. Hair Star Indonesia. Variabel tunjangan juga berpengaruh positif dan signifikan terhadap produktivitas tenaga kerja produksi PT. Hair Star Indonesia. Tunjangan merupakan pendorong semangat kerja bagi tenaga kerja, karena tenaga kerja merasa lebih dihargai dan diperhatikan dengan adanya tunjangan yang diberikan. Sedangkan usia berpengaruh negatif dan signifikan terhadap produktivitas tenaga kerja produksi PT. Hair Star Indonesia. Hal tersebut membuktikan bahwa semakin tinggi usia tenaga kerja, maka semakin menurun produktivitas tenaga kerja PT. Hair Star Indonesia. Ada beberapa saran yang dapat dijadikan referensi dalam upaya meningkatkan produktivitas tenaga kerja produksi PT. Hair Star Indonesia, yaitu mempertahankan sistem pemberian insentif dan perlu juga adanya penambahan nominal pada pemberian insentif agar dapat lebih meningkatkan produktivitas tenaga kerja. Tunjangan juga harus tetap diberikan kepada tenaga kerja serta dilakukan 
peningkatan agar tenaga kerja merasa dihargai oleh perusahaan dan semakin meningkatkan produktivitas tenaga kerja. Dalam proses perekrutan tenaga kerja, usia tenaga kerja harus masuk dalam usia angkatan kerja atau dalam usia produktif, tidak boleh di bawah usia kerja dan tidak boleh lebih dari usia kerja agar dapat meningkatkan produktivitas dan hasil kerja terbaik.

\section{DAFTAR PUSTAKA}

Ajija, Shochrul Rohmatul, dkk. 2011. Cara Cerdas Menguasai EViews. Jakarta: Salemba Empat.

Amron dan Taufiq Imran. 2009. "Analisis Faktor - Faktor yang Berpengaruh Terhadap Produktivitas Tenaga kerja Outlet Telekomunikasi Seluler Kota Makassar”. Dalam Jurnal Ekonomi. Makassar: Sekolah Tinggi Ilmu Ekonomi Nobel Indonesia.

Arfida, Dra. BR, M.S. 2003. Ekonomi Sumber Daya Manusia. Jakarta: Ghalia Indonesia.

Arikunto, Suharsimi. 2002. Metodologi Penelitian. Jakarta: Rineka Cipta.

--------- 2006. Metodologi Penelitian. Jakarta: Bumi Aksara.

Arsyad, Lincolin. 2004. Ekonomi Pembangunan. Yogyakarta: STIE YKPN.

Badan Pusat Statistik (BPS) Kabupaten Sidoarjo. 2016. Kabupaten Sidoarjo Dalam Angka 2015. Sidoarjo: Badan Pusat Statistik.

Batubara, Khairunnisa., Ir. Sugiharto Pujangkoro, MM, dan Buchari, ST, M.Kes. 2013. "Pengaruh Gaji, Upah, dan Tunjangan Karyawan Terhadap Kinerja Karyawan Pada PT. XYZ". Dalam Jurnal Teknik Industri, Vol. 3 No.5 Hal. 23-28. Medan: Fakultas Teknik USU.

Darmawan, R. Ibnu. 2008. Analisis Penetapan Insentif Pelayanan Tenaga Perawat. Tesis. Semarang: Magister Ilmu Kesehatan Masyarakat UNDIP.

Dessler, Gary. 200o. Human Resource Management 8th. New Jersey: Prentice Hall, Inc.

El-Gohary, K. dan R. Aziz. 2014. "Critical Review of Labor Productivity Research in Egypt" Dalam Journal of Management Engineering, Vol.30 No.1 Hal. 1-9. Virginia: ASCE

Firmansyah, Zakaria. 2015. Analisis Pengaruh Umur, Pendidikan, dan Upah Terhadap Produktivitas Tenaga Kerja pada Mitra kerja Industri Rambut di Kabupaten Purbalingga. Skripsi. Semarang: Fakultas Ekonomi UNNES.
Ghozali, Imam. 2011. Aplikasi Analisis Multivariate dengan Program IBM SPSS 19. Semarang: Badan Penerbit Universitas Diponegoro.

Gorda, IGN. 2004. Manajemen Sumber Daya Manusia. Singaraja: STIE Satya Dharma. Gujarati, Damodar. 2007. Dasar-Dasar Ekonometrika. Jakarta: Erlangga.

Hadiyanto. 2012. Pengaruh Insentif Material dan Non Material terhadap Ketersediaan Tenaga Kesehatan di Kabupaten Bogor. Tesis. Jakarta: Program Magister Ilmu Kesehatan Masyarakat UI.

Handoko, T. Hani. 200o. Manajemen Personalia dan Sumber Daya Manusia, Edisi II. Yogyakarta: BPFE.

--------- 2002. Manajemen Personalia dan Sumber Daya Manusia, Edisi II. Yogyakarta: BPFE.

Hariandja, Marihot T.E. 2002. Manajemen Sumber Daya Manusia. Jakarta: Grasindo.

Harsono. 1987. Manajemen Publik Cetakan Kedua. Jakarta: Ghalia Indonesia.

-- 2004. Perencanaan Program Latihan. Jakarta: KONI Pusat.

Hasibuan, Malayu S.P. 1996. Organisasi Dan Motivasi, Dasar Peningakatan Produktivitas, Bumi. Jakarta: Aksara Putra.

---------- 1997. Manajemen Sumber Daya Manusia. Jakarta: Gunung Agung.

--------- 200o. Manajemen Sumber Daya Manusia. Yogyakarta: STIE YKPN.

-- 2009. Manajemen Dasar, Pengertian dan Masalah Edisi Revisi. Jakarta: Bumi Aksara.

Indriyani, Agustina. 2014. Analisis Pengaruh Gaji dan Tunjangan Kesejahteraan Terhadap Produktivitas Kerja Karyawan Operation Department PT. Export Leaf Indonesia. Dalam Jurnal Paradigma, Vol. 12 No. 1 Hal 7-11. Surakarta: Universitas Islam Batik Surakarta.

Irawan dan Suparmoko. 1992. Ekonomika Pembangunan. Yogyakarta: BPFE.

Jahrie, Fikri dan S. Hariyoto. 1999. Human Resources Management (Manajemen Sumber Daya Manusia). Jakarta: AIMI.

Koontz, Harold dan Cyril O’Donnel dan Heinz Weihrich. 1986. Manajemen. Jilid 2. Terjemahan: Gunawan Hutauruk. Jakarta: Erlangga.

Kussriyanto, Bambang. 1986. Meningkatkan Produktivitas Karyawan, Edisi II. Jakarta: LPPM dan Pustaka Binaan.

Mankiw, N. Gregory. 2001. Pengantar Ekonomi, Jilid II. Jakarta: Erlangga. 
Manullang, M. 1994. Manajemen Personalia. Jakarta: Ghalia Indonesia.

Mazura, Mujiono dan Rosmida. 2012. Pengaruh Insentif terhadap Kinerja Pegawai Negeri Sipil (Studi Kasus pada Badan Kepegawaian Daerah Kabupaten Bengkalis). Dalam Jurnal Ilmiah Mahasiswa, Vol. 1 No.1 Hal. 19-27. Bengkalis: Politeknik Negeri Bengkalis.

Meier, M.G. 1995. Leading Issues in Economics Development, Sixth Edition. Singapore: Mc. Graw Hill.

Moekijat. 1999. Manajemen Sumber Daya Manusia (Manajemen Kepegawaian). Bandung: Mandar Maju.

Mulyadi. 2003. Sistem Akuntansi. Jakarta: Salemba Empat.

Muryanto, Eko. 2011. Pengaruh Kompensasi Terhadap Kinerja Dengan Motivasi Kerja Sebagai Variabel Moderating. Skripsi. Surakarta: Fakultas Ekonomi UNS.

Nasir, Nadia. 20o8. Analisa Pengaruh Tingkat Upah, Masa Kerja,Usia Terhadap Produktivitas Tenaga Kerja (Studi Kasus Pada Tenaga Kerja Perusahaan Rokok "Djagung Padi" Malang). Skripsi. Malang: Fakultas Ekonomi Universitas Brawijaya.

Nofrinaldi, Meilala, A dan Utarini A. 2006. Persepsi dan Pembagian Sistem Pembagian Jasa Pelayanan terhadap Kinerja Karyawan di Rumah Sakit Jiwa Madani. Bagian Ilmu Kesehatan Masyarakat. Yogyakarta: Fakultas Kedokteran UGM.

Nurmawanto, Slamet. 2014. Pengaruh Insentif Terhadap Produktivitas Kerja di Kantor (Representatif Office) PT. Asuransi Takaful Keluarga Cipulir. Skripsi. Jakarta: Fakultas Ilmu Dakwah dan Ilmu Komunikasi UIN Syarif Hidayatullah.

Panggabean, Mutiara. 2002. Manajemen Sumber Daya Manusia. Cetakan Pertama. Jakarta: Ghalia Indonesia.

Robbins. 20o1. Perilaku Organisasi: Konsep, Kontraversi, Aplikasi. Jilid I. Jakarta: Prenhalindo.

Sari, E., \& Farah, A. (2014). Modal Manusia dan Produktivitas. JEJAK:Jurnal Ekonomi dan Kebijakan, $7(1)$, 22-28. doi:http://dx.doi.org/10.15294/jejak.v7i1.3840

Sevilla, C. G.et. al. 196o. Research Methods. Quezon City: Rex Printing Company. Simamora, Henry. 1997. Manajemen Sumber Daya Manusia. Yogyakarta: STIE YKPN.
--------- 2001. Manajemen Sumber Daya Manusia. Yogyakarta: STIE YKPN.

Simanjuntak, Payaman. 1998. Pengantar Ekonomi Sumber Daya Manusia. Jakarta: Lembaga Penerbit Fakultas Ekonomi Universitas Indonesia.

--------- 2005. Manajemen dan Evaluasi Kinerja. Jakarta: Lembaga Penerbit Fakultas Ekonomi Universitas Indonesia.

Singarimbun, M. dan Effendi, S. (Ed). 1986. Metode Penelitian Survai. Jakarta: Pustaka LP3ES Indonesia.

Sinungan, Muchdarsyah. 1992. Produktivitas Apa Dan Bagaimana. Jakarta: Bumi Aksara.

200o. Produktivitas Apa Dan Bagaimana. Jakarta: Bumi Aksara.

Sudarmanto. 2009. Kinerja dan Pengembangan Kompetensi SDM (Teori, Dimensi Pengukuran dan Implementasi dalam Organisasi). Yogyakarta: Pustaka Pelajar.

Sugiyono, 2003. Metode Penelitian Bisnis. Bandung: Alfabeta.

2009. Metode Penelitian Kuantitatif, Kualitatif dan R \& D. Bandung: Alfabeta.

Sumarsono, Sonny. 2003. Ekonomi Manajemen Sumber Daya Manusia dan

Ketenagakerjaan. Yogyakarta : Graha Ilmu.

Suwatno dan Priansa, Donni. 2011. Manajemen SDM dalam Organisasi Publik dan Bisnis. Bandung: Alfabeta.

Todaro, Michael. P. 200o. Ekonomi Untuk Negara Berkembang. Jakarta: Erlangga.

Ude, Dr. Ugwu dan Dr. M. A. Coker. 2012. Incentive Schemes, Employee Motivation and Productivity In Organizations In Nigeria. Dalam Journal of Business and Management, Vol.1 No.4 Hal. 32-39. Cross River State: University of Calabar.

Umar, Husein. 1999. Sumber Daya Manusia Dalam Organisasi. Jakarta: Gramedia Pustaka Utama.

Wartana, I Made Hedy. 2011. Faktor-Faktor yang Mempengaruhi Produktivitas Kerja Karyawan Pada Como Shambala Estate At Begawan Giri Ubud Bali. Dalam Jurnal Perhotelan dan Pariwisata, Vol.1 No.1 Hal.2o. Badung: STIPAR Triatma Jaya.

Wungu, Jiwo dan Brotoharsojo, Hartanto. 2003. Tingkatkan Kinerja Perusahaan Anda dengan Merit System. 2003. Jakarta: Raja Grafindo Persada.

www.sidoarjonews.com 2015 Investasi Tembus 22,8 Trilyun, Sidoarjo Raih Invesment Award Kembali.. 


\section{APPENDIX}

Tabel 5. Regresi Linear Berganda

Dependent Variable: PRODUKTIVITAS

Method: Least Squares

Date: 12/12/16 Time: 11:07

Sample: 186

Included observations: 86

\begin{tabular}{|c|c|c|c|c|}
\hline Variable & Coefficient & Std. Error & t-Statistic & Prob. \\
\hline C & 80.86766 & 7.044328 & 11.47983 & 0.0000 \\
\hline LOG(INSENTIF) & 71.54116 & 2.522889 & 28.35685 & 0.0000 \\
\hline TUNJANGAN & 0.288829 & 0.132697 & 2.176613 & 0.0324 \\
\hline USIA & 0.015895 & 0.020530 & 0.774221 & 0.4410 \\
\hline R-squared & 0.942973 & \multicolumn{2}{|c|}{ Mean dependent var } & 321.1860 \\
\hline Adjusted R-squared & 0.940887 & \multicolumn{2}{|c|}{ S.D. dependent var } & 8.120434 \\
\hline S.E. of regression & 1.974338 & \multicolumn{2}{|c|}{ Akaike info criterion } & 4.243739 \\
\hline Sum squared resid & 319.6369 & \multicolumn{2}{|c|}{ Schwarz criterion } & 4.357894 \\
\hline Log likelihood & -178.4808 & \multicolumn{2}{|c|}{ Hannan-Quinn criter. } & 4.289681 \\
\hline F-statistic & 451.9730 & \multirow{2}{*}{\multicolumn{2}{|c|}{ Durbin-Watson stat }} & 1.887977 \\
\hline Prob(F-statistic) & 0.000000 & & & \\
\hline
\end{tabular}

Sumber: Data diolah EViews 6 